\title{
KARATER MAJELIS SEBAGAI PEMIMPIN JEMAAT MENURUT 1 TIMOTIUS 3:8-10 DI GEREJA GPPIK MARANATHA ANTAN PONTIANAK KALIMANTAN BARAT"
}

\author{
Julianus Zaluchu ${ }^{1)}$ Nita Ulansari ${ }^{2)}$ \\ 1) Sekolah Tinggi Teologi injili indonesia - Surabaya \\ E-mail: julianuszaluchu@sttii-surabaya.ac.id \\ 2) STT Bethany - Surabaya \\ E-mail: nitaulansari16@yahoo.com
}

\begin{abstract}
A key word that is very important and often used in the sphere of Church life is the word 'ministry'. This word has a very deep meaning, not only because the word 'ministry' has its roots in and is rooted in Jesus Christ, whose whole life fully qualifies the meaning of service. But also by realizing that by and through the word 'ministry', the Church has emerged as a unique, unique and specific institution, which cannot be found in common with any other institution that has come together in the middle of history. In other words, the terminology of ministry has a close affinity for the church, although in recent developments the term ministry itself has been widely used in the life of non-ecclesiastical institutions. The presence of the churches in Indonesia is not a passive and meaningless presence. The presence of the church in Indonesia is a dynamic, active presence that moves, a presence that is directed to others, a presence that serves. The church will lose its meaning if its presence in the world becomes a passive, static, non-serving presence.
\end{abstract}

Keywords: Character, Congregation Leader, Congregation

\begin{abstract}
Abstrak
Sebuah kata kunci yang sangat penting dan acapkali dipergunakan dalam ruang lingkup kehidupan Gereja adalah kata 'pelayanan'. Kata ini mengandung makna yang sangat dalam, bukan saja oleh karena kata 'pelayanan' bersumber serta berakar pada Yesus Kristus, yang keseluruhan hidup-Nya mengkualisasikan secara prima arti pelayanan. Tetapi juga dengan menyadari bahwa oleh dan melalui kata 'pelayanan' itu, Gereja telah tampil sebagai sebuah intitusi yang khas, unik dan spesifik, yang tak bisa dicari kesamaannya dengan intitusi lain yang bersama-sama hadir di tengah-tengah sejarah. Dengan kata lain, terminologi pelayanan memiliki ketertarikan erat dengan gereja,walaupun dalam perkembangan terakhir istilah pelayanan itu sendiri, telah banyak dipergunakan dalam kehidupan lembagalembaga non gerejawi. Kehadiran gereja-gereja di Indonesisa bukanlah kehadiran yang pasif dan tanpa makna. Kehadiran gereja di bumi Indonesia justru merupakan sebuah kehadiran yang aktif dinamik, yang bergerak, kehadiran yang terarah bagi orang lain, kehadiran yang melayani. Gereja akan kehilangan maknanya jika kehadiraanya di tengah dunia menjadi kehadiran pasif, yang statis, yang tidak melayani.
\end{abstract}

Kata Kunci: Karakter, Pemimpin Jemaat, Jemaat 


\section{PENDAHULUAN}

Gereja adalah persekutuan yang Allah nyatakan untuk melayani, untuk berkarya di tengah dunia yang konkret. Untuk dapat melayani dengan tepat, terarah dan relevan, maka Gereja harus memahami dengan baik kondisi-kondisi yang ada disekitarnya. Dalam buku yang berjudul "Gereja-gereja dalam Pelayanan"1 yang mempunyai arti yang sangat penting sebagai salah satu yang akan membantu Gereja-gereja dalam mewujudkan tugas pelayanan secara optimal di tengah-tengah jemaat dan masyarakat. ${ }^{2}$ Gereja adalah perwujudan ajaran Kristus, ajaran-Nya bukan hanya untuk diucapkan tapi juga untuk perlihatkan secara nyata di dalam kehidupan masyarakat. Gereja bukan hanya merupakan hasil doktrin Kristus, tapi merupakan bukti nyata kepercayaan. Gereja adalah masyarakat Kristen yang dijumpai kapan saja dan di mana saja. Karena itu gereja bukan sekedar suatu organisasi individu yang

${ }^{1}$ Soenarto Martowirjono, Gereja-Gereja Dalam Pelayanan (Surakarta: Krida Aksara,1992), 5 ${ }^{2}$ Ibid. percaya pada Yesus, tapi juga suatu organisme. Karena itu Dia bisa menyebutnya Gereja $\mathrm{Ku}$, dan Paulus menyebutnya tubuh Yesus. Bagian tersulit dari doktrin gereja adalah menghilangkan semua salah paham dan citra-citra mental buruk yang sudah melanda. Sangat perlu membersihkan pikiran dan mulia lagi dengan membiarkan Alkitab dan Roh Kudus menafsirkannya untuk kita. ${ }^{3}$

Sementara Gereja punya banyak arti, suatu bangunan, suatu jemaat, suatu denominasi, profesi yang di tekuni oleh ulama-ulama atau masyarakat Kristen secara menyeluruh, dalam Perjanjian Baru kelihatanya hanya ada satu arti, yaitu yang disebut terakhir itu. Namun, ini memerlukan beberapa kualifikasi agar dengan demikian kita bisa juga mengatakan bahwa gereja dilihat dari dua aspek, universal dan lokal: pertama, Gereja universal- terdiri dari semua orang Kristen, hidup dan mati, lepas dari prasangka denominasi mereka, suku,

\footnotetext{
${ }^{3}$ Michael Griffiths, Gereja Dan Panggilannya Dewasa Ini (Jakarta: BPK Gunung Mulia, 1995), 1-2.
} 
kebangsaan atau status sosial. Kedua :

Gereja Lokal- dengan pengecualian dari nats-nats yang sudah disebut dalam Efesus, hampir setiap acuan lainya bertemu secara teratur di tempat yang sama dan dengan kepemimpinan yang wewenangnya diakui oleh jemaat secara keseluruhan. ${ }^{4}$

Dalam setiap kebudayaan dan zaman, pasti menemukan kata-kata yang menyampaikan suatu gambaran yang lebih dinamis tentang Gereja. Di tahun enampuluhan, demonstrasi-demonstrasi mahasiswa merupakan suatu contoh yang bermanfaat, sehingga David Miichell mengatakan: "Gereja Tuhan merupakan suatu tubuh yang harus berdemonstrasi sepanjang waktu, mendemonstrasikan kasih Allah".5

Teologi praktis mengedepankan aspek relasi antara teori dengan praktik, antara eksistensi dengan fungsi. Dalam kaitannya dengan eklesiologi yaitu studi tentang gereja, teologi praktis berusaha menjelaskan relasi antara teori tentang gereja dengan praktik bergereja, antara eksitensi gereja dengan fungsi gereja ini

${ }^{4}$ Ibid, 10.

${ }^{5}$ Michael Griffiths, Gereja Dan Panggilannya Dewasa Ini (Jakarta: BPK Gunung Mulia, 1995), 13-14. penting karena mendasari kesadaran setiap orang percaya untuk hidup bergereja dan mengambil bagian dalam pelayanan sesuai talenta yang diberikan Tuhan kepadanya demi tercapainya visi, misi dan tujuan gereja. Dengan pengenalan tentang hakikat dan fungsi manajemen Gerjea maka perlu melihat ruang lingkup dan isi manajemen gereja serta pengelolaannya. ${ }^{6}$

Dalam pelayanan di Gereja GPPIK Maranatha Antan Pontianak Kalimantan Barat, di samping majelis juga dijumpai penatua gereja dan penasehat gereja. Para pengurus ini berkerjasama dalam melayani Tuhan misalnya: menyambut tamu (usher), kolektan, menyampaikan warta jemaat, pengumuman, melayani perjamuan kudus. Hal ini dilaksanakan setiap hari minggu pada saat ibadah, di gereja GPPIK Maranatha Antan juga memiliki sistem kepemimpinan yang berbeda dengan gereja-gereja lain, misalnya: yang memiliki kuasa atas gereja dan jemaat bukan lah Gembala sidang

\footnotetext{
${ }^{6}$ Andreas Untung Wiyono, Manajemen Gereja (Bandung: Bina Media Imformasi,2010), v-vi.
} 


\section{METODE PENELITIAN}

Dalam metode penelitian untuk mendukung pembahasan dalam penelitian ini, penulis menggunakan metode penelitian kualitatif dengan pendekatan deskriptif. Penelitian kualitatif $^{7}$ adalah penelitian yang bermaksud untuk memahami fenomena tentang apa yang dialami oleh subjek penelitian misalnya, perilaku, persepsi, motivasi, tindakan dan lain-lainnya. Dengan cara deskripsi ${ }^{8}$ dalam bentuk kata-kata dan bahasa, pada suatu konteks khusus yang alamiah dan dengan memafaatkan berbagai metode alamiah. ${ }^{9}$ Sedangkan pendekatan terhadap metode kualitatif digunakan pengumpulan data melaui Perpustakaan ${ }^{10}$ dan lapangan. ${ }^{11}$

Sedangkan prosedur penelitian yang digunakan dalam penelitian ini adalah sebagai berikut: Pertama, untuk menjawab pertanyaan peneliti tentang karakter hamba Tuhan menurut 1Timotius 3:8-10, maka

\footnotetext{
${ }^{7}$ Andreas B. Subagyo, Pengantar Riset Kuantitatif dan Kualitatif (Bandung: Kalam Hidup, 2004), 53. Menyatakan bahwa, untuk menyediakan prinsipprinsip umum, menetapkan fakta, meningkatkan pengetahuan dan pengertian, menepatkan atau menafsierkan dengan lebih baik, memecahkan masalah yang membingungkan dan menjawab pertanyaan-pertanyaan yang sebelumnya tidak terjawab, serta menyediakan teori.

${ }^{8}$ Kasus disajikan secara ringkas dan padat dalam susunan yang jelas, serta dirumuskan secara subjektif tanpa terlalu banyak rumusan interpretative dan analistis.
}

penulis mengumpulkan data tentang defenisi karakter menurut 1Timotius 3:8-10 pada bab dua, dengan cara mencari dari linteratur teologi, buku-buku serta kamuskamus yang ada di perpustakaan.

Kedua, untuk menjawab pertanyaan penelitian, penulis mengumpulkan data, dengan cara terjunlangsung ke lapangan, membuat pertanyaan wawancara, sumber literatur sejarah para pengurus gereja GPPIK Maranatha Antan Pontianak, Kalimantan Barat pada bab tiga.

Ketiga, untuk menjawab pertanyaan penelitian ketiga, mengenai karakter hamba Tuhan menurut 1Timotius 3:8-10dan penerapanya di gereja GPPIK Maranatha Antan Pontianak, Kalimantan Barat, maka penulis mengabungkan data yang terdapat pada bab dua dan bab tiga.Dalam penulisan ini, penulis mengunakan rancangan penelitian sebagai berikut:

Pertama, Penulis melihat secara langsung bagaimana keadaan yang terjadi di lapangan dengan memperhatikan pelayanan yang di

9 Lexy J. Moleong, Metodologi Penelitian Kualitataif (Bandung:PT.Remaja Rosdakarya, 2007),6.

${ }^{10}$ Andreas B. Subagyo, Pengantar Riset Kuantitatif dan Kualitatif, 198 menyatakan bahwa, peneliti harus memperhatikan dengan meninjau dan memadukannya dari hasil-hasil penelitian sebelumnya.

${ }^{11}$ Melakukan pengamatan dan berintraksi dengan subjek.Andreas B. Subagyo, Pengantar Riset Kuantitatif dan Kualitatif, 229. 
laksanakan oleh para pengurus jemaat dan sifat sesuatu yang sedang diteliti. Kedua, melakukan pendekatan dengan mengajukan pertanyaan (wawancara) kepada setuap pengurus jemaat di Gereja GPPIK Maranatha Antan Pontianak, Kalimantan Barat. Ketiga, melakukan penelitian keperpustakaan berdasarkan I Timotius 3:8-10, dengan melakukan eksegese, prinsip hermeneutika dengan kritik teks untuk menemukan arti yang dimaksud sesungguh dengan teks aslinya. ${ }^{12}$

Keempat, menganalisa data yang telah ada untuk mengetahui masalah yang mendominan yang terjadi di lapangan. Kelima, membuat validasi daftar Keperpustakaan kepada dosen pembimbing. Keenam, mengumpulkan semua data yang memberikan gambaran umum tentang kebenaran Firman Tuhan mengenai karakter hamba Tuhan berdasarkan I Timotius 3:8-10.

\section{HASIL DAN PEMBAHASAN}

Penelitian yang besifat studi evaluasi ini bertujuan untuk memberikan pemahaman terhadap pengurus jemaat mengenai yang benar akan pentingnya setiap persyaratan dan karakter menurut

${ }^{12}$ Gordon D. Fee \& Douglas Stuart, Hermeneutika: Bagaimana Menafsirkan Firman Tuhan Dengan Tepat, (Malang:Gandum Mas, 1982),2.
1Timotius 3:8-10 agar terjadi peningkatan kualitas pelayananan rohani di Gereja GPPIK Maranatha Antan Pontianak, Kalimantan Barat. Dengan demikian setiap pengurus bukan hanya mempunyai pengetahuan dan kecakapan untuk melayani, tetapi terlebih lagi adalah bagaimana memaknai peran sebagai alatNya Tuhan. ada dua bagian yang penulis tekankan disini yaitu: Pertama,Bertujuan untuk memberi pemahaman terhadap Pengurus jemaat mengenai pentingnya karakter untuk melayani Tuhan.

Kedua, Bertujuan untuk mendapat gambaran tentang bagaimana sikap seorang Pengurus jemaat Tuhan menurut 1Timotius $3: 8-10$.

Manfaat dari hasil penelitian ini dapat dilihat dari dua sudut pandang, yaitu kepentingan teoritis dan kepentingan praktis. Kepentingan penelitian harus dilihat dari segi teoritis, yaitu sumbangansumbangan yang dapat diberikan kepada dunai ilmu pengetauan. Kepentingan praktis yaitu sumbangan-sumbangan yang dapat diberikan penerapan ilmu pengetauan ${ }^{13}$.

Pertama,penelitian ini memberi kontribusi bagi pembentukan karakter pengurus jemaat dalam pelayanan menurut

\footnotetext{
${ }^{13}$ Andreas B. Subagyo, Pengantar Riset Kuantitatif dan Kualitatif: Termasuk Riset Teologi dan Keagamaan (Bandung: Yayasan Kalam Hidup,2004), 215
} 
1Timotius 3:8-10 di Gereja GPPIK

Maranatha Antan Pontianak Kalimantan

Barat. Kedua, penelitian ini akan memberi gambaran mengenai bagaimana seharusnya karakter pengurus jemaat menurut 1 Timotius 3:8-10 di Gereja GPPIK Maranatha Antan Pontianak Kalimantan Barat. Ketiga,penelitian ini memberi pemahaman bagi pelayan Tuhan sebagai hamba serta menerapkannya sebagai konsep hamba Tuhan yang memiliki karakter yang baik dalam dunia pelayanan.

Penelitian ini memmiliki tiga kepentingan praktis: Pertama, hasil penelitian ini dapat menjadi pedoman bagi setiap hamba Tuhan, pemimpin gereja, maupun organisasi-organisasi yang terjun di dunia pelayanan untuk memiliki karakter hamba Tuhan sesuai Alkitabiah khususnya bagi para hamba Tuhan yang melayani di gereja GPPIK Maranatha Antan Pontianak Kalimantan Barat.

Kedua, hasil penelitan ini dapat memberi penjelasan tentang pentingnya memahami Allah sebagai pemberi sekaligus pembentuk karakter bagi para hamba Tuhan yang melayani di gereja GPPIK Maranatha Antan Pontianak Kalimantan Barat.

Ketiga, hasil penelitian ini bisa memberikan kesadaran kepada para hamba Tuhan bahwa memiliki karakter yang baik sangatlah penting apalagi sebagai hamba Tuhan yang Allah percayakan untuk melayani.

\section{KESIMPULAN}

Setelah melaksanakan penelitian lapangan, maka dapat diambil suatu kesimpulan. Penelitian ini disusun untuk menjawab beberapa pertanyaan penelitian yaitu:

Pertama, Bagaimanakah saudara menanggapi mengenai orang yang terhormat? Menurut 1 Timotius 3:8-18 bagi Majelis di gereja GPPIK Maranatha Antan Pontianak Kalimantan Barat? Berdasarkan hasil wawancara dan analisis data menyatakan bahwa yang di katakan orang terhormat adalah orang yang memiliki nama baik, bersiakp bijaksana serta santun dalam bersikap.

Kedua, Apakah pemimpin jemaat itu harus memiliki integritas didalam hidupnya menurut 1 Timotius 3:8-18 bagi Majelis di gereja GPPIK Maranatha Antan Pontianak Kalimantan Barat? Berdasarkan hasil wawancara dan analisis data menyatakan bahwa yang di katakan memiliki integritas ialah Seorang pemimpin harus berintegritas, apa yang dikatakan itulah yang diperbuat.

Ketiga, Apakah yang harus dilakukan apabila pemimpin jemaat ketahuan menjadi penggemar anggur menurut 1 Timotius 3:818 bagi Majelis di gereja GPPIK Maranatha Antan Pontianak Kalimantan Barat? Berdasarkan hasil wawancara dan analisis 
data menyatakan Karena alkohol tidak bagus untuk tubuh.

Keempat, Bagaimanakah sikap dan tindakan saudara ketika mengetahui pemimpin jemaat saudara memiliki sikap serakah menurut 1 Timotius 3:8-18 bagi Majelis di gereja GPPIK Maranatha Antan Pontianak Kalimantan Barat? Berdasarkan hasil wawancara dan analisis data menyatakan Memberi nasehat yang baik, serta bersikap tegas agar tidak mempengaruhi yang lainya dan Menyampaikan kepada penatua dan pihak gereja yang berwewenagn dalam mengatasi pemimpin atau majelis yang melangar.

Kelima, Bagaimanakah seorang pemimpin jemaat menjaga kehidupannya agar tetap dalam kekudusan serakah menurut 1 Timotius 3:8-18 bagi Majelis di gereja GPPIK Maranatha Antan Pontianak Kalimantan Barat? Berdasarkan hasil wawancara dan analisis data menyatakan Hidup intim dengan Tuhan, berjalan bersama Tuhan serta merendahkan hati di hadapan Tuhan.

\section{IMPLIKASI}

Implikasi untuk Majelis di gereja GPPIK Maranatha Antan Pontianak Kalimantan Barat sebagai berikut:

Pertama, agar setiap Majelis atau pemimpin jemaat gereja GPPIK Maranatha Antan Pontianak Kalimantan Barat bisa memahami lebih lagi mengenai fungsi seorang pemimpin jemaat dengan baik.

Kedua, supaya setiap pemimpin jemaat gereja GPPIK Maranatha Antan Pontianak Kalimantan Barat yang sudah memimpin lebih memahami bagaimana seharusnyan bersikap selayaknya menjadi patnernya Allah dalam membina umat yang telah Allah percayakan.

Ketiga, supaya pemimpin jemaat yang ada di gereja GPPIK Maranatha Antan Pontianak Kalimantan Barat harus hidup dalam kekudusan serta memiliki sikap yang berintgritas.

\section{DAFTAR PUSTAKA}

[1] A.A. Sitompuldan Ulrich Beyer, Metode Penafsiran Alkitab. Jakarta: PT. BPK Gunung Mulia, 2006.

[2] Andreas B. Subagyo, Pengantar Riset Kuantitatif dan Kualitatif: Termasuk Riset Teologi dan Keagamaan Bandung: Yayasan Kalam Hidup,2004.

[3] Pengantar Riset Kuantitatif dan Kualitatif. Bandung: Kalam Hidup, 2004.

[4] Andreas Untung Wiyono, Manajemen Gereja. Bandung: Bina Media Imformasi,2010 
[5] A.S. Hornby, Oxford Advanced Learner's Dictionary of Current English.London: Oxford University Press, 1974.

[6] Bimo Walgito,

PengantarPsikologiUmum. Yogyakarta: ANDI,2010.

[7] B. S. Sidjabat, Membangun Pribadi Unggul Suatu Pendekatan Teologis Terhadap Pendidikan Karaakter Yogyakarta:ANDI, 2011.

[8] Budiman, Surat Pastoral 1 dan 2 Timotiusdan Titus. Jakarta:BPKGunungMulia, 1997.

[9] Daniel C. Arichea, Surat-surat Paulus Kepada Timotius Dan Kepada Titus. Jakarta: Yayasan Karunia Bakti Budaya Indonesia,2004.

[10] D.A. Carson, Douglas J. Moo, dan Leon Morris, New Testament Theology. Michigan: Zondervan Publishing House, 1986.

[11] Donald C. Stamps, Alkitab Penuntun Hidup Berkelimpahan.

[12] Edwin D. Freed, The New Testament: A Critical Introduction.. USA: Wardsworth, 1986.
[13] Gordon D. Fee \& Douglas Stuart, Hermeneutika: Bagaimana Menafsirkan Firman Tuhan Dengan Tepat, .Malang:Gandum Mas, 1982

MembangunKarakterAnda. Zoschak, Immanuel, 1991.

[15] Hasan Sutanto, Hermeneutik: Prinsipdan Metode Penafsiran Alkitab.

[16] Hasan Susanto, Perjanian Baru Interlinear Yunani Indonesia dan Konkordasi Perjanjian Baru Jakarta:LAI, 2002.

[17] J.D. Douglas, Ensiklopedia Alkitab Masa Kini. Jakarta: Yayasan Komunikasi Bina Kasih/OMF,2002.

[18] John Mc.Clintock \& James Strong, Cycopedia of Biblical Theological, and Eccleasiastical Linterature.Grand Rapids : BakerBook House Company,1981.

[19] Juanda, J. (2017). Melayani Kristus Dengan Karya Tulis. Journal Kerusso, 2(1), 45-54.

[20] Juanda, Juanda. "Pengaruh Kelas Pendalaman Iman Anak Lebak Arum 
Jurnal Teologi \& Pelayanan ( Kerusso )

E-ISSN: 2714-9587

P-ISSN: 2407-554X

(Piala) Terhadap Pertumbuhan Rohani

Anak Usia 11-14 Tahun Di Kompleks

Perumahan Lebak Arum Surabaya." Journal

Kerusso 1.1 (2016): 51-56.

[21] Kamus Bahasa Indonesia Pusat Bahasa

Edisi Keempat. Jakarta: Gramedia Pustaka Umum

[22] Les Carter, PembentukanKarakter.

Bandung: YayasanBaptis Indonesia, 1995.

[23] Lexy J. Moleong, Metodologi Penelitian Kualitataif.Bandung:PT.Remaja Rosdakarya, 2007.

[24] Mary Setiawani \& Stephen Tong, Seni Membentuk Karakter Kristen. Jakarta: Lembaga Reformed Injili Indonesia,1995.

[25] Matthew Black, Analytical Greek New Testament. Michigan: Baker Book House Grand Rapids, 1981.

[26] Merrill.C Tenny, Survei Perjanjian Baru. Malang: Gandum Mas,2006.

[27] Michael Griffiths, Gereja Dan Panggilannya Dewasa Ini. Jakarta: BPK Gunung Mulia, 1995.

[28] Prasetyo, Widi, et al. "Measuring the Quality of God's Servants According to
Acts 6: 3 At the Surabaya City Tabernacle Pentecostal Church." Journal KERUGMA 2.1 (2019): 24-33.

[29] Ridwan, Metode dan Teknik Penyususnan Tesis. Bandung: alfabet,2007.

[30] Rumiyati, Rumiyati, et al. "Pengaruh Kepemimpinan Hamba Tuhan Dalam Pertumbuhan Kerohanian Jemaat Gereja GPdI 'Zion'Krebet, Tembalang, WlingiBlitar." Journal Kerusso 3.2 (2018): 9-19.

[31] Samuel Benyamin, Perjanjian Baru: Sejarah, Pengantar dan Pokok-pokok Teologisnya.Bandung: Bina Media Informasi, 2010.

[32] Soedarmo, Tafsiran 2 Timotius. Jakarta : BPK Gunung Mulia,2008.

[33] Soenarto Martowirjono, Gereja-Gereja Dalam Pelayanan. Surakarta: Krida Aksara,1992

[34] Stephen Tong, Arsitek Jiwa II. Jakarta: Lembaga Reformed Injili Indonesia,1993.

[35] Todd J. Murphy, Poket Dictionary for The Study of Biblical Hebrew. USA: Inter Varsity Press, 1999.

[36] Widianto, K., Permana, S., \& Juanda, 
Jurnal Teologi \& Pelayanan ( Kerusso )

E-ISSN: 2714-9587

P-ISSN: 2407-554X

J. (2019). The Effect of Church Community

Development and Pastoral Services on The

Growth of The Congregation of The Bethel

Indonesia Church, Family Blessing

Surabaya. Journal KERUGMA, 2(2), 1-21.

[37] Wirawan Acen, Pembentukan-

Karakter -Kristen-1,

http://reportaselshadai. wordpress.com, diunduh Pada Hari Kamis tanggal 20 April 2016.

[38] Yakub Tomatala, Manusia Sukses.

Malang:Gandum Mas,1998.

[39] Yakob Tomatala, Kepemimpinan Yang

Dinamis. Jakarta: YT Leadership

Foundation 1997. 